\title{
On North Pacific Multidecadal Climate Variability
}

\author{
MojiB LATIF \\ Leibniz-Institut für Meereswissenschaften, Kiel, Germany
}

(Manuscript submitted 22 March 2005, in final form 4 October 2005)

\begin{abstract}
The multidecadal climate variability in the North Pacific region is investigated by using a 2000 -yr-long integration with a coupled ocean-atmosphere general circulation model. It is shown that the multidecadal variability evolves largely independent of the variations in the tropical Pacific, so that this kind of multidecadal variability may be regarded as internal to the North Pacific. The coupled model results suggest that the multidecadal variability can be explained by the dynamical ocean response to stochastic wind stress forcing. Superimposed on the red background variability, a multidecadal mode with a period of about $40 \mathrm{yr}$ is simulated by the coupled model. This mode can be understood through the concept of spatial resonance between the ocean and the atmosphere.
\end{abstract}

\section{Introduction}

Coherent multidecadal atmospheric and oceanic variability in the North Pacific climate system has been described in many papers (see e.g., Mantua et al. 1997; Zhang and Levitus 1997; Tourre et al. 1999, 2001; Deser et al. 2004). The North Pacific sea level pressure (SLP) index (Trenberth and Hurrell 1994), for instance, defined as the average over the region $30^{\circ}-65^{\circ} \mathrm{N}$ and $160^{\circ} \mathrm{E}-140^{\circ} \mathrm{W}$, exhibits substantial multidecadal variability. Likewise, the Pacific decadal oscillation (PDO) index also shows strong multidecadal variability (Fig. 1). The PDO index is defined as the leading principal component of North Pacific monthly sea surface temperature (SST) variability poleward of $20^{\circ} \mathrm{N}$. There have been a number of studies published that investigated the observed global SSTs using EOF, complex EOF, or rotated EOF (REOF) analyses (see e.g., Mestas-Nuñez and Enfield 1999, and references therein). Although, the analyses and results differ in various ways, all these EOF-based studies confirm the existence of a multidecadal mode in the North Pacific that shows only weak connections to the Tropics (see e.g., REOF mode 5 of Mestas-Nuñez and Enfield 1999).

The origin of multidecadal variability observed in the

Corresponding author address: Mojib Latif, Leibniz-Institut für Meereswissenschaften, Düsternbrooker Weg 20, D-24105 Kiel, Germany.

E-mail: mlatif@ifm-geomar.de
North Pacific region, however, is still a matter of intense scientific debate. Trenberth and Hurrell (1994), Graham (1994), Zhang et al. (1997), Gu and Philander (1997), and Deser et al. (2004) argue that the North Pacific multidecadal variability is forced by variations in the tropical Pacific through atmospheric teleconnections. But, Latif and Barnett (1994) and Barnett et al. (1999) claim, mostly by analyzing model simulations, that its origin is in the North Pacific itself and that air-sea interactions within the North Pacific climate system are important. Different versions of Hasselmann's (1976) stochastic climate model were also proposed to explain the decadal variability in the extratropical oceans. Frankignoul et al. (1997), for instance, argue that the decadal variability in the extratropical oceans can be explained by the dynamical response to stochastic wind stress forcing. Finally, Saravanan and McWilliams (1998) discuss another stochastic mechanism of decadal variability in the midlatitude oceanatmosphere system that produces a defined time scale in the ocean. This mechanism, which is referred to as the concept of spatial resonance, is based only on a fixed spatial structure of atmospheric forcing and on a constant ocean advective velocity.

The origin of the multidecadal variability in the North Pacific climate system is investigated further in this paper. The term multidecadal is defined here in a loose way describing variability on time scales of several decades. A clear periodicity cannot be defined from observations because the observed records are 


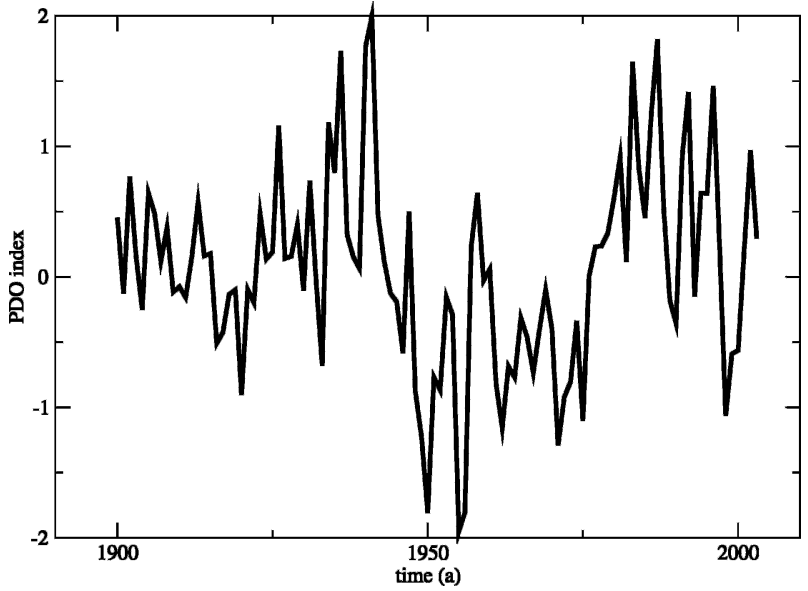

FIG. 1. Time series of the PDO index. The PDO index is defined as the principal component of the leading EOF of annual North Pacific SST anomalies poleward of $20^{\circ} \mathrm{N}$.

simply too short. Two fundamental questions are addressed in this study. First, does multidecadal variability require remote forcing from the Tropics or can it originate in the North Pacific itself? Second, do largescale air-sea interactions in the midlatitudes play an important role in the dynamics of the multidecadal variability?

Because the observational database is insufficient to explore the nature of the multidecadal variability in detail, the output of a 2000-yr-long integration with the ECHAM3/LSG coupled general circulation model (CGCM) is investigated to get further insight into the dynamics of the North Pacific multidecadal variability. Such long coupled model integrations enable a statistically meaningful description of the multidecadal variability. It should be noted that coupled models exhibit large biases, so the results should be taken with some caution. The paper is organized as follows. The model and the analyzed model data are described in section 2. The coupled model results are presented in section 3 . The summary and a brief discussion are presented in section 4.

\section{Model data}

The model data are taken from a 2000-yr-long control integration of the ECHAM3/LSG CGCM with constant present-day greenhouse gas concentrations. The coupled model is described in detail by Voss et al. (1998). Timmermann et al. (1998) investigated the North Atlantic interdecadal variability and Timmermann et al. (1999) describe the El Niño-Southern Oscillation (ENSO)-like variability and its low-frequency modulation in the ECHAM3/LSG CGCM. Grötzner et al. (1999) used the same coupled model to investigate the interannual to decadal predictability globally. The CGCM is a coarse resolution model: The atmosphere model ECHAM3 is run at a horizontal resolution of $\mathrm{T} 21\left(5.6^{\circ} \times 5.6^{\circ}\right)$, while the ocean model LSG employs a horizontal resolution of about $4^{\circ} \times 4^{\circ}$. The coupled model is flux corrected. As outlined by Timmermann et al. (1999), the ENSO-like variability simulated by this coarse-resolution model is too weak, but its space-time structure compares well with observations.

Annual mean values are analyzed from the coupled model run. All analyses were also performed with seasonal data, but the main results remained unchanged. In particular, the analysis for winter (DecemberFebruary; DJF) yields very similar results compared with that obtained from the annual mean analysis. The annual mean anomaly patterns are basically identical to the corresponding winter patterns. The strength of the anomalies in winter, however, is much stronger relative to that derived from the annual mean data, with winter anomalies exceeding the annual mean anomalies typically by about $30 \%-40 \%$. Because the main variability patterns did not change and given the long time scales considered, it is justified to restrict the investigation of the simulated multidecadal variability to the annual mean anomalies, especially when considering the slow motions in the upper ocean. Here, upper-ocean heat content anomalies are computed from the temperatures of the upper $575 \mathrm{~m}$.

\section{Coupled model results}

The observational database, which covers only the last $150 \mathrm{yr}$, is insufficient to explore the nature of the North Pacific multidecadal variability. A way out of this dilemma is the use of long coupled model simulations such as the 2000-yr-long integration of the ECHAM3/ LSG CGCM. Such a long integration yields many realizations of the multidecadal variability and thus provides a good starting point to study its dynamics. The coupled model simulates pronounced multidecadal variability in the North Pacific, as shown by the annual SST anomalies in the northwestern Pacific $\left(35^{\circ} \mathrm{N}\right.$, $150^{\circ} \mathrm{E}$ ) during the full $2000 \mathrm{yr}$ (Fig. 2). Also shown is the 11-yr running mean to highlight the multidecadal variability. This index was chosen because it is located in the center of action of SST variability (see Fig. 4a). The spectrum of the full 2000-yr-long SST anomalies (SSTA) time series (Fig. 3a) is basically red up to multidecadal time scales. However, it exhibits a statistically significant peak (above the $95 \%$ level) at a period of about $40 \mathrm{yr}$, which suggests the existence of a multidecadal mode in the coupled model. The period was also 
(a)

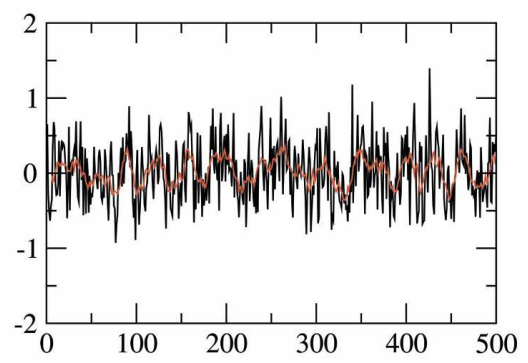

(c)

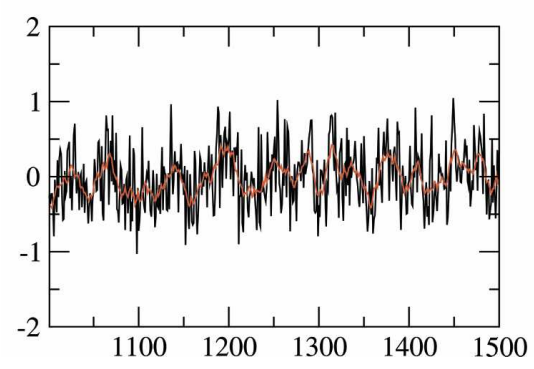

(b)

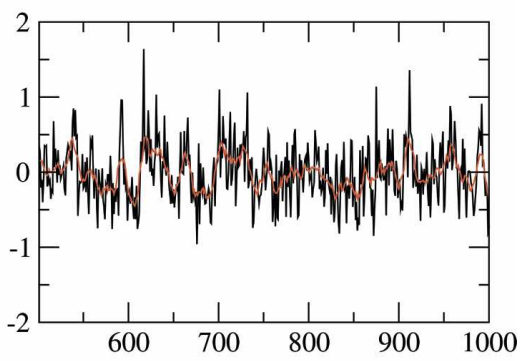

(d)

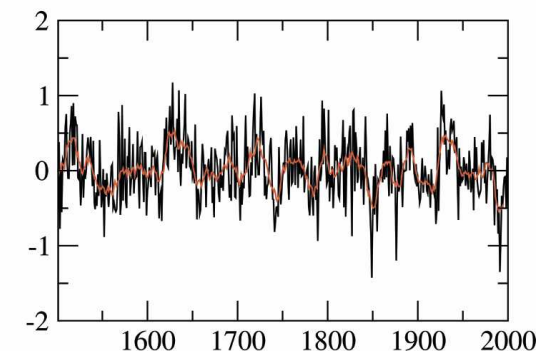

FIG. 2. Annual mean SST anomalies (K; black line) in the northwestern Pacific $\left(35^{\circ} \mathrm{N}\right.$, $150^{\circ} \mathrm{E}$ ) simulated by the ECHAM3/LSG model. Also shown is the 11-yr running mean (red line) to highlight the multidecadal variability. The linear trend was removed.

checked by singular spectrum analysis (SSA), and the leading SSA mode, representing the multidecadal mode, has a similar period. The coupled model's period is within the uncertainty of the observed period of the multidecadal variability, as discussed above (Fig. 1), and it is rather robust. Different statistical methods (e.g., wavelet analysis) and window lengths were used, and all results confirm the period of about $40 \mathrm{yr}$. The dynamics of the 40-yr mode are discussed below.

Spectra of selected atmospheric quantities were com- puted next, and they are largely consistent with those expected from a white noise process. An example is shown in Fig. $3 b$ that depicts the spectrum of the zonal wind stress anomalies at $35^{\circ} \mathrm{N}, 150^{\circ} \mathrm{E}$, the same location the SST spectrum was computed. The spectral characteristics of oceanic and atmospheric quantities thus support the hypothesis of Frankignoul et al. (1997) that the multidecadal variability can be understood basically as the North Pacific Ocean's dynamical response to stochastic wind stress forcing. This response involves the
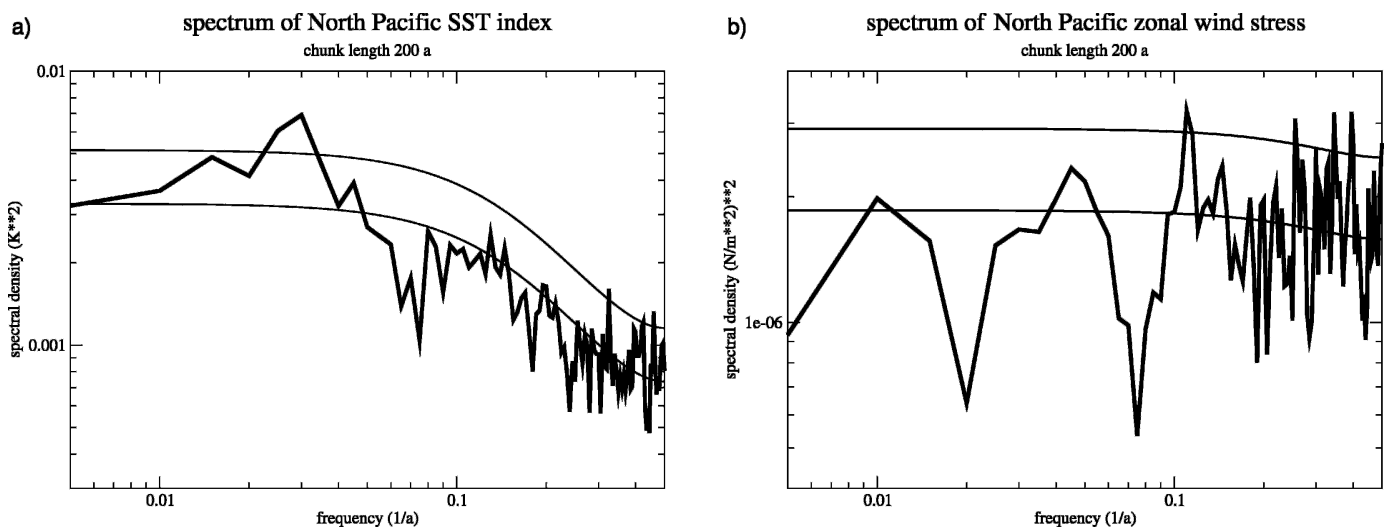

FIG. 3. Spectrum of the (a) SSTA time series shown in Fig. 2 and (b) zonal wind stress anomalies. A BlackmanTukey procedure was used with a chunk length of $200 \mathrm{yr}$. The corresponding spectrum of an autoregressive process of the first order (AR-1) process and the $95 \%$ significance level are also given. 
adjustment of gyre circulations, in particular the propagation of baroclinic Rossby waves. The coupled model used in this study is much more complex than the linear model used by Frankignoul et al. (1997), but the spectral characteristics of the variability simulated by the ECHAM3/LSG CGCM are basically consistent with those expected from linear theory. It is concluded from the spectral analyses that the applicability of the linear stochastic concept extends well into the multidecadal time scales.

It should be mentioned that the multidecadal variability in the model undergoes strong centennial-scale modulations (Fig. 2), which confirms the need to study rather long time series. Clearly, records of many centuries length are needed to obtain a clear picture of the multidecadal variability. The period around and after the year 1500 , for instance, is a rather quiescent period concerning the multidecadal mode and is governed by a rather strong centennial-scale fluctuation (Fig. 2).

A secondary peak is seen in the spectrum of the North Pacific SST index at interannual time scales when a smaller window length is used, and this is related to the model's El Niño-like variability. The strength of the interannual variability in the Tropics, however, is considerably underestimated in the coupled model because of its coarse resolution (Timmermann et al. 1999), but it is strong enough to exert a statistically significant impact on the North Pacific through changes in the Aleutian low. The weak El Niño-like variability may be of some advantage in this study because one can regard this coupled model experiment as a kind of sensitivity experiment, in which the Tropics play a minor role. The existence of strong North Pacific multidecadal variability in the coupled model simulation suggests that this kind of multidecadal variability can be generated in the North Pacific region itself, and that it does not necessarily require remote forcing from the tropical Pacific.

The time series of the anomalous northwestern SST (Fig. 2) is used as a reference time series in the following. Area-averaged time series were also used, but the results did not change in any significant manner. An area-averaged SSTA index was computed as the average over the region $25^{\circ}-40^{\circ} \mathrm{N}$ and $140^{\circ}-170^{\circ} \mathrm{E}$. The correlation of this index with the point index shown in Fig. 2 amounts to about 0.9. Thus, it is justified to use the point index as a reference time series to describe the multidecadal variability. The spatial patterns of different quantities associated to the northwestern SST time series are derived by linear regression. The domain considered is the Pacific Ocean from $30^{\circ} \mathrm{S}$ to $60^{\circ} \mathrm{N}$.

The simulated SST anomaly pattern (Fig. 4a) is similar to the observed structure shown in many papers (e.g., Zhang et al. 1997). The main positive anomaly is located in the region $30^{\circ}-40^{\circ} \mathrm{N}$ and is surrounded by anomalies of opposite sign. The center of action, however, is simulated somewhat further to the west. Important to the discussion of the origin of the North Pacific multidecadal variability is the fact that the model does not show any statistically significant relationship to the tropical Pacific, a result that was also obtained in various observational studies (e.g., Mestas-Nuñez and Enfield 1999). The regression pattern of the upper-ocean heat content (averaged over the upper $575 \mathrm{~m}$ ) is similar to that of the SST, as shown in Fig. 4b. The negative anomaly in the subtropics, however, extends further to the west. Like the SST, the upper-ocean heat content does not show any statistically significant connection to the tropical Pacific. There is, however, some hint of weak interhemispheric symmetry in both anomalous SST and upper-ocean heat content. Wave propagation and reflection at the eastern boundary are likely to produce this symmetry. The upper-ocean heat content is discussed in greater detail below, when the dynamics of the multidecadal variability are discussed.

Some selected atmospheric anomaly fields are shown in Figs. 4c-f. The SLP anomaly pattern (Fig. 4c) is shifted to the northeast relative to the main SST anomaly, with anomalously high pressure associated with anomalously warm surface waters. This is consistent with many of the observational analyses (e.g., Trenberth and Hurrell 1994) and describes a weakening of the model's Aleutian low in association with anomalously warm North Pacific SSTs. The center of the SLP anomaly is located near the date line at about $45^{\circ} \mathrm{N}$. The associated zonal wind stress anomaly pattern (Fig. 4d) is also consistent with that found in the observations (e.g., Mestas-Nuñez and Enfield 1999). However, like the simulated SST anomaly pattern, the simulated zonal wind stress anomaly pattern is also shifted somewhat to the west relative to the observations. The maximum zonal wind stress anomaly coincides basically with the maximum SST anomaly, which indicates that anomalous Ekman heat transport contributes to the SST tendency. Note that the effects of wind mixing on the SST are not included in the coupled model, and this may be the reason that the main model SST anomaly does not extend as far to the east as in the observations.

The anomalous wind stress curl and net surface heat flux patterns are shown in Figs. 4e,f. Both the wind stress curl anomaly pattern (Fig. 4e) and the net surface heat flux anomaly pattern (Fig. 4f) suggest that the SST anomaly is not forced by these two quantities in most regions because the two anomaly patterns do not correspond well to the SST anomaly pattern. In the western North Pacific, however, which is the region of the 
a)

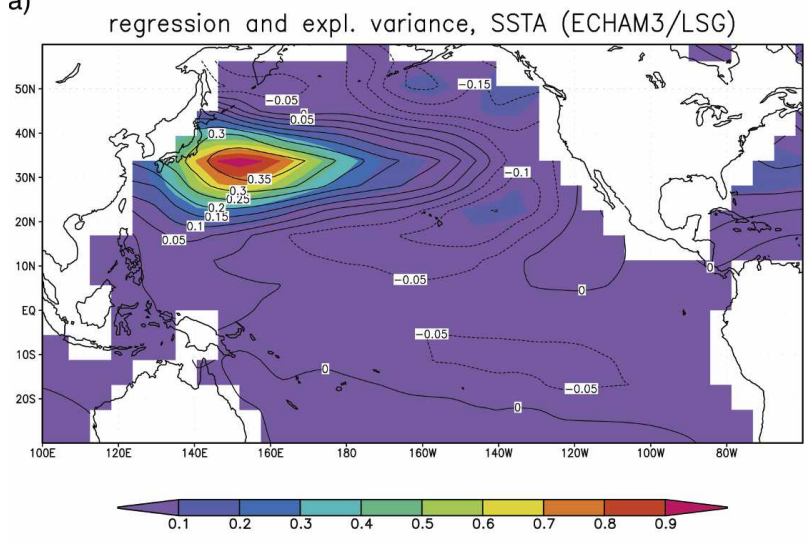

GrADS: COLA/IGES

c)

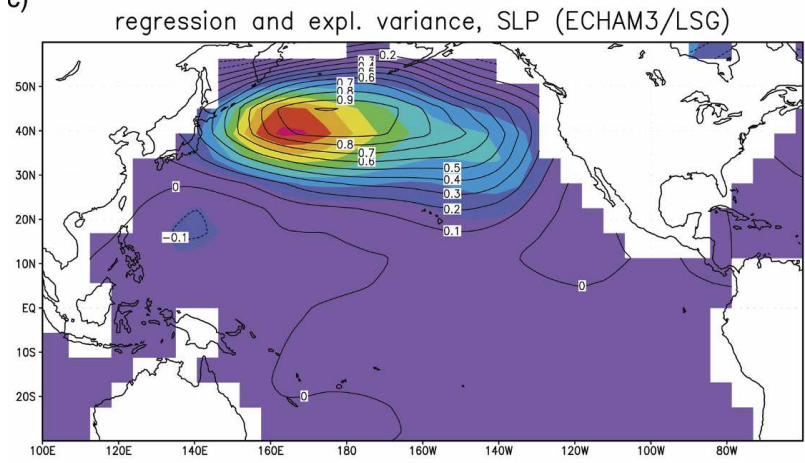

GrAS: COLA/IGES

e)

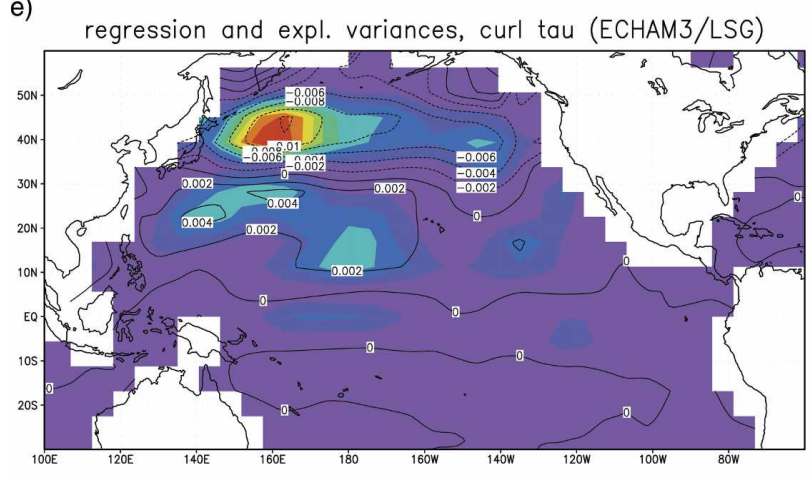

\begin{tabular}{ccccccccc}
\hline & & & & & & & & \\
0.03 & 0.06 & 0.09 & 0.12 & 0.15 & 0.18 & 0.21 & 0.24 & 0.27
\end{tabular} b)

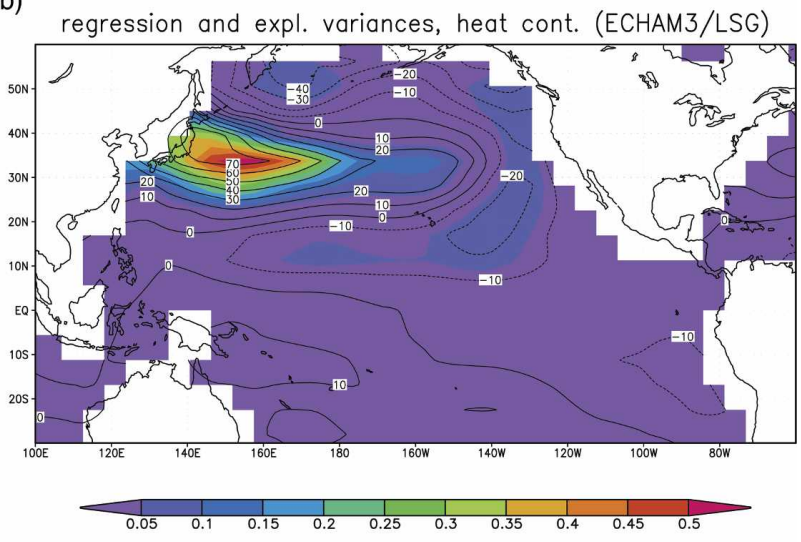

GrADS: COLA/IGES

d)

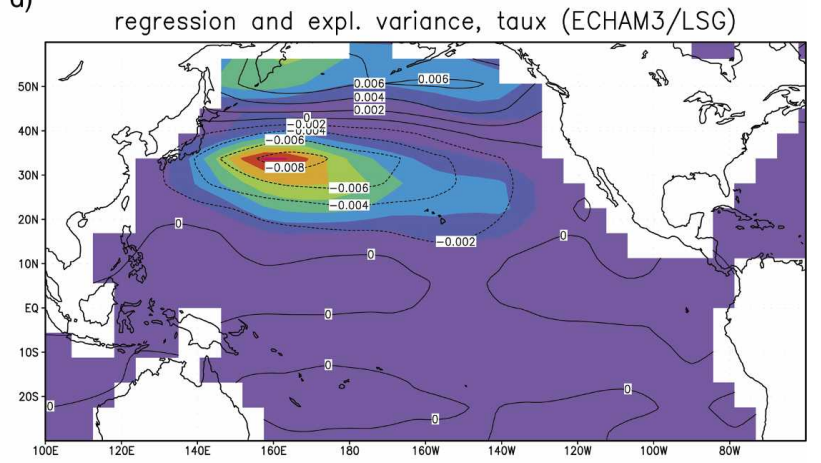

MDS: COLA/GES

f)

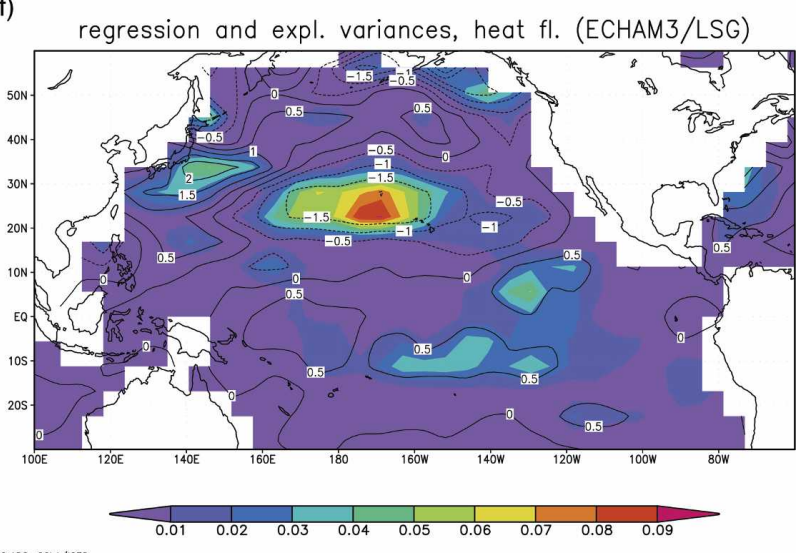

GrADS: COLA/GES

FIG. 4. Maps of linear regression coefficients of anomalous (a) SST (K), (b) upper-ocean heat content $\left({ }^{\circ} \mathrm{C} \mathrm{m}\right)$, (c) SLP (hPa), (d) zonal wind stress $\left(\mathrm{N} \mathrm{m}^{-2}\right),(\mathrm{e})$ wind stress curl $\left[\left(\mathrm{N} \mathrm{m}^{-2}\right) \mathrm{m}^{-1}\right]$, and (f) net surface heat flux $\left(\mathrm{W} \mathrm{m}^{-2}\right)$ with respect to the SST index shown in Fig. 2. Contours denote the regressions and color the explained variances. Anomalies corresponding to a one standard deviation change of the SST index are shown.

strongest SST anomaly, the net surface heat flux anomaly contributes to the surface warming. The positive heat flux anomaly can be explained by the anticyclonic circulation simulated over the North Pacific (Fig. $4 c$ ), which drives southerly surface winds that advect warm air to the north. The wind stress curl anomaly in the eastern subtropical North Pacific forces enhanced Ekman upwelling that, in association with the negative heat flux anomalies, drives the negative SST anomalies in this region. In most other regions the net surface heat 
flux tends to damp the SST anomalies, so that ocean dynamics must play an important role in the generation of the anomalous North Pacific SST. For instance, the strong negative heat flux anomaly in the central Pacific near the date line at $20^{\circ}-30^{\circ} \mathrm{N}$, which is likely to result from enhanced evaporation in response to stronger westerlies (Fig. 4d), tends to damp the SST anomalies (Fig. 4a).

Overall, the space-time structure of the coupled model's multidecadal variability is consistent with that derived from observational studies, with the caveat that the anomalies are too concentrated in the west in comparison with the observed anomalies. Nevertheless, it is believed that the coupled model results can be used to help to understand the dynamics of the observed North Pacific multidecadal variability. Of particular importance to the dynamics of the multidecadal variability is the wind stress curl anomaly pattern that exhibits a dipolar structure, with anomalies of opposite signs poleward and equatorward of about $30^{\circ} \mathrm{N}$. As described by Venzke et al. (2000) conducting periodically forced ocean model simulations, the adjustment of the North Pacific to such a dipolar forcing pattern is quite complex and involves wave propagation and advective processes.

To get further insight into the dynamics of the multidecadal variability, lag correlations were computed between the northwestern SSTA index (Fig. 2) and the upper-ocean heat content anomalies, and they are displayed as correlation fields at different lags (Fig. 5) and as Hovmoeller diagrams for two latitude bands (Fig. 6). The correlation fields show snapshots four years apart from each other, starting with lag zero, which is the warm phase in the North Pacific. At lag zero, a positive heat content anomaly is simulated in the western North Pacific that is surrounded by negative anomalies. The negative anomalies to the south of the warm anomaly propagate slowly westward, as seen in the lag 4-yr correlation field. A negative anomaly can then be seen in the region of the model's Kuroshio and its extension (lags 8 and $12 \mathrm{yr}$ ) and it grows thereafter (lag $16 \mathrm{yr}$ ). At this time, the phase reversal is almost completed. At lag $8 \mathrm{yr}$, the negative anomaly has basically disappeared. However, there is simulated a rather strong gradient in the heat content in the region $20^{\circ}-30^{\circ} \mathrm{N}$ in the western part of the basin at this time. This indicates a weakening of the Kuroshio extension that subsequently leads to a negative heat content anomaly along the axis of the Kuroshio extension, as can be seen at lag $12 \mathrm{yr}$.

The picture that emerges from the temporal evolution of the heat content anomalies can be summarized as follows. The positive wind stress curl anomalies in the region $10^{\circ}-30^{\circ} \mathrm{N}$ (Fig. $4 \mathrm{e}$ ) lead to an adjustment of the subtropical gyre, which involves Rossby wave propagation, and eventually a new Sverdrup balance is established. The new Sverdrup balance is associated with reduced strength of the Kuroshio and its extension that leads to negative heat content anomalies in this region. The Rossby wave propagation is seen best in the heat content anomalies, but not well in the SST (not shown), while the anomalies along the axis in the Kuroshio extension are seen well in both the heat content and the SST anomaly fields (not shown). Thus, the temperature signal is hidden at subsurface levels during most of the adjustment process and reappears at the surface when the adjustment of the subtropical gyre is basically complete.

The two Hovmoeller diagrams clearly show the quasi-periodic nature of the heat content anomalies, although no bandpass-filtering was applied, which confirms the existence of a multidecadal mode with a period of about $40 \mathrm{yr}$. A pronounced westward propagation of the upper-ocean heat content anomalies over several years that precedes the development of the SST anomalies further to the north is seen in the subtropics $\left(20^{\circ}-30^{\circ} \mathrm{N}\right.$; Fig. 6a). As outlined by Venzke et al. (2000), the westward propagation can be interpreted as the propagation of baroclinic Rossby waves that are forced by the anomalous wind stress curl at this latitude (Fig. 4e). There is evidence of eastward propagating heat content anomalies in the eastern part that are probably due to advection of SST anomalies, which are forced by local heat flux anomalies (Fig. 4f), by the mean circulation. The westward propagation is not seen in the SST, which is dominated by a standing component in the latitude band $20^{\circ}-30^{\circ} \mathrm{N}$ (not shown). There is about a 2-yr phase lag between the arrival of the Rossby wave signal at the western boundary and the SST farther to the northeast. This phase lag arises from anomalous temperature advection within the Kuroshio extension region (see Fig. 5).

Farther to the north $\left(30^{\circ}-40^{\circ} \mathrm{N}\right)$, there is some indication of eastward propagating heat content anomalies (Fig. 6b). This eastward propagation results from advection of the upper-ocean temperature anomalies in the region of the Kuroshio extension, in which the anomalous wind stress curl is rather weak (Fig. 4e). This part of the propagation is seen also in the SST, but not in any of the atmospheric forcing fields (not shown). Even farther to the north, the behavior of the upper-ocean heat content is again dominated by westward propagating anomalies (not shown), which is consistent with Rossby waves forced by the wind stress curl anomalies simulated in this region. In summary, only the anomalous upper-ocean heat content shows a consistent temporal evolution, with a clockwise rotation of 

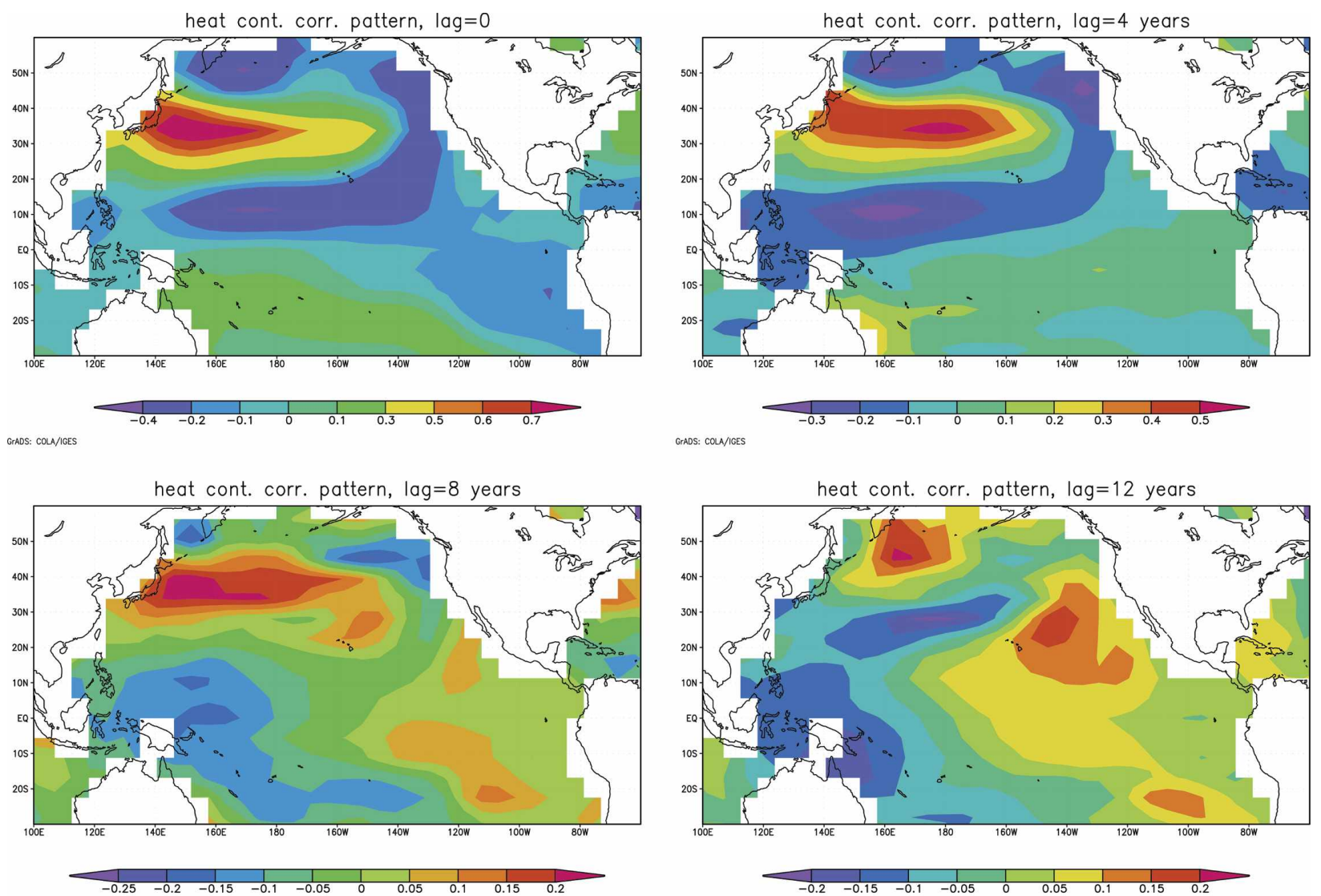

GrADS: COLA/GES

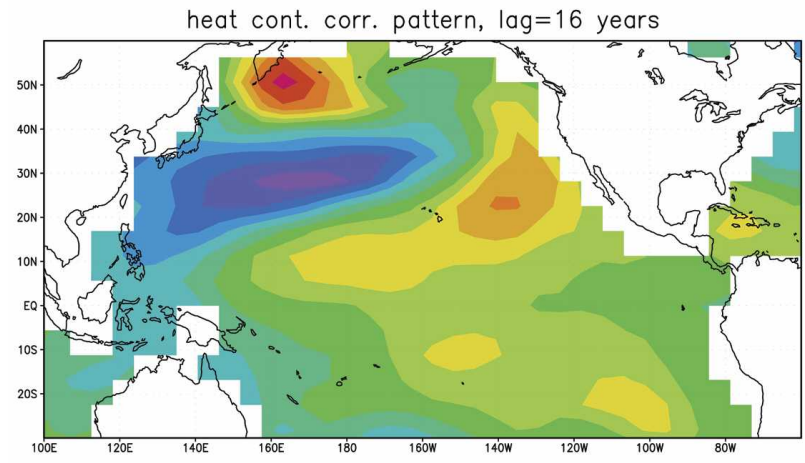

FIG. 5. Lag correlations of the northwestern Pacific SST index $\left(35^{\circ} \mathrm{N}, 150^{\circ} \mathrm{E}\right)$ shown in Fig. 2 and the upper-ocean heat content anomalies. Shown are the correlation fields four years apart from each other (lags $0,4,8,12$, and $16 \mathrm{yr}$ ).

GrADS: COLA/GES

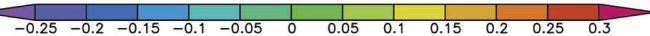

the anomalies in the subtropical gyre. Neither the atmospheric fields nor the SST exhibit such an evolution.

One should note that the correlations shown in Figs. 5 and 6 are relatively weak, which indicates that the multidecadal mode in the model is strongly damped. This is also supported by the study of Grötzner et al. (1999) who used the same coupled model to investigate the interannual to decadal predictability globally by performing an ensemble of classical predictability experiments. They found relatively low predictability of

SST anomalies in the North Pacific region at decadal time scales.

Because the atmospheric variables show neither a preferred time scale (see e.g., Fig. 3b) nor any propagation, a stochastic concept may be adopted to explain the preferred periodicity of $40 \mathrm{yr}$ in the coupled model. As outlined by Saravanan and McWilliams (1998), atmospheric variability on long time scales occur as spatially fixed patterns. Here the atmospheric variability is associated with fluctuations in the strength of the Aleu- 
a) corr. of SST index with heat cont. (20-30N)

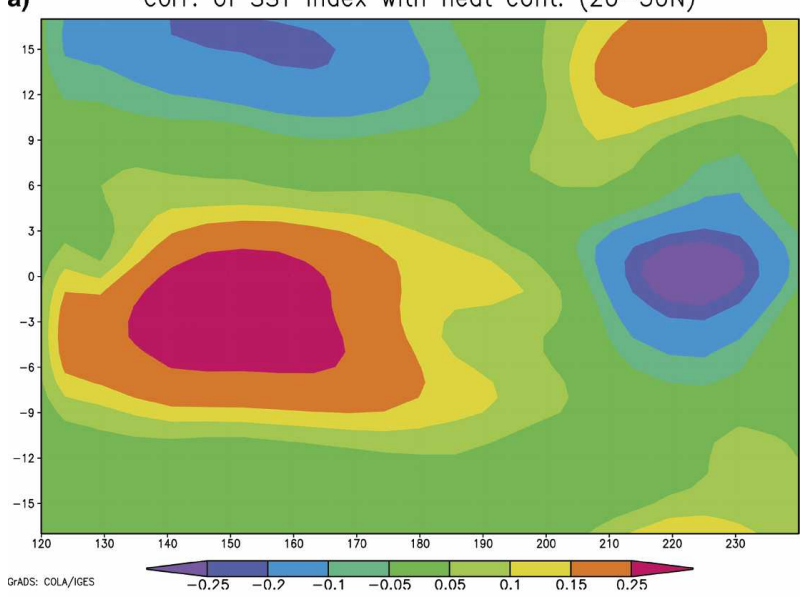

b) corr. of SST index with heat cont. (30-40N)

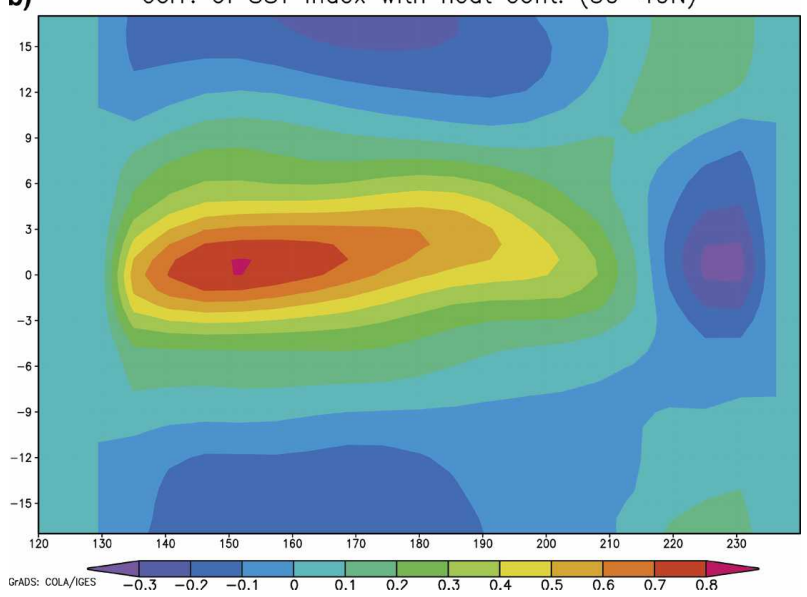

FIG. 6. Correlations of the northwestern Pacific SST index $\left(35^{\circ} \mathrm{N}, 150^{\circ} \mathrm{E}\right)$ shown in Fig. 2 and the upper-ocean heat content anomalies averaged over the latitude band (a) $20^{\circ}-30^{\circ} \mathrm{N}$ and (b) $30^{\circ}-40^{\circ} \mathrm{N}$ as function of longitude and time lag (yr). A 5-yr running mean filter was applied prior to the correlation analysis.

tian low (Fig. 4c). These fluctuations are associated with anomalies in the air-sea fluxes (Figs. 4d,e,f). Given a characteristic length scale of the atmospheric variability and mean advection in the ocean, resonance can occur at a defined time scale. The picture here is similar, but with one important difference. The mean advection is replaced by the overall adjustment of the ocean to wind stress curl variations. The adjustment will produce SST anomalies along the path of the Kuroshio and its extension, which will be reinforced by the air-sea fluxes at a defined time scale that depends on the ocean's adjustment time. In the western North Pacific, it is basically the anomalous surface heat flux and the zonal wind stress anomalies (through anomalous Ekman heat transport) that contribute to the SST tendency. Thus, the 40-yr periodicity is a result of the full ocean adjustment and the stochastic, but spatially co- herent, atmospheric variability, and it involves different air-sea fluxes, rather than just the surface heat flux. The signal is hidden at subsurface levels during most of the adjustment, and the interaction with the atmosphere occurs when the strength of the subtropical gyre has changed and the temperature signal is seen again at the surface.

\section{Summary and discussion}

A 2000-yr-long coupled model simulation was analyzed to study the dynamics of the multidecadal variability in the North Pacific. The main results are first, the multidecadal variability is largely consistent with the stochastic climate model scenario, proposed originally by Hasselmann (1976), in which the ocean responds passively to the stochastic atmospheric forcing. Accordingly, ocean spectra such as SST spectra are red up to multidecadal time scales, while atmospheric spectra are basically white. In contrast to the simplest stochastic model, in which the ocean mixed layer is forced by the surface heat flux anomalies, it is the ocean dynamics in the coupled model simulation discussed here that respond to stochastic wind stress anomalies, as hypothesized by Frankignoul et al. (1997), and this produces the long multidecadal time scales. Second, remote forcing from the Tropics is not required to generate the multidecadal variability in the North Pacific in this particular coupled model. This result, however, certainly does not rule out the possibility that the Tropics are important in forcing North Pacific multidecadal variability in the real world.

Furthermore, the model results indicate that a mode with a multidecadal period of about $40 \mathrm{yr}$ exists in the North Pacific that is superimposed on a red background variability. A plausible explanation for the existence of this mode is the spatial resonance hypothesis of Saravanan and McWilliams (1998). However, in contrast to the study of Saravanan and McWilliams (1998), it is the full ocean adjustment in response to the variations in the air-sea fluxes rather than just the mean advection that sets the preferred time scale. In principle, the proposed scenario is a special case of that put forward by Latif and Barnett (1994). The feedback from the ocean to the atmosphere that is important in the study of Latif and Barnett (1994) does not play any role in the spatial resonance scenario described here. Thus, the sensitivity of the atmosphere to North Pacific SSTA is an important parameter that controls the behavior of the coupled system. Whether the real North Pacific climate system resides in the uncoupled regime described here or in the coupled regime described by Latif and Barnett (1994) is still an open question. The instrumental data 
of North Pacific SST and SLP show some (anti) correlation on multidecadal time scales that is consistent with the coupled scenario of Latif and Barnett (1994). The two observed records, however, are certainly too short to make a statistically meaningful statement about their phase relationship on multidecadal time scales. The same is true for the relationship between the North Pacific multidecadal variability to that in the tropical Pacific. Observations indicate some connection (e.g., Deser et al. 2004), but this could well be incidental, as shown below.

Unfortunately, long observational records of ocean heat content do not exist, so the important role of the ocean adjustment in response to the wind stress curl variations could be shown here only by a long coupled model simulation and not by observations. The upperocean heat content variability from the 2000-yr-long coupled model integration presented here shows a characteristic evolution in the upper-ocean heat content, and it is concluded from the coupled model run that the ocean's memory carries the coupled system from one phase of the multidecadal mode to the other. Some evidence from heat content observations for such a behavior does exist, as described by Zhang and Levitus (1997) and Venzke et al. (2000).

Instrumental and paleoclimatic observations show enhanced atmospheric multidecadal variability over the North Pacific and North America, while the corresponding model spectra are white. There are basically three reasons that could explain this difference. First, the scenario of Latif and Barnett (1994) applies to the real world, in which the variability originates from large-scale air-sea interactions. Such a picture would yield enhanced multidecadal variability in both the ocean and the atmosphere. Second, the enhanced atmospheric multidecadal variability is forced by the Tropics, in the same way as ENSO drives interannual variability. Last, external forcing, such as multidecadal solar variability, is responsible for the enhanced atmospheric multidecadal variability. Air-sea coupling and tropical variability are rather weak in and external forcing absent from the coupled model presented here, so that some underestimation of the multidecadal variability in the extratropical atmosphere is to be expected.

An interesting statistical question that can be addressed by analyzing a multicentury long coupled model integration concerns the stability of correlations between the Tropics and the Midlatitudes. The correlation between the low-pass filtered (applying an 11-yr running mean filter) eastern equatorial Pacific (Niño-3) SST anomaly and the North Pacific SST anomaly index was analyzed using a 398-yr-long sliding window. The results (Fig. 7) show that the correlation is generally

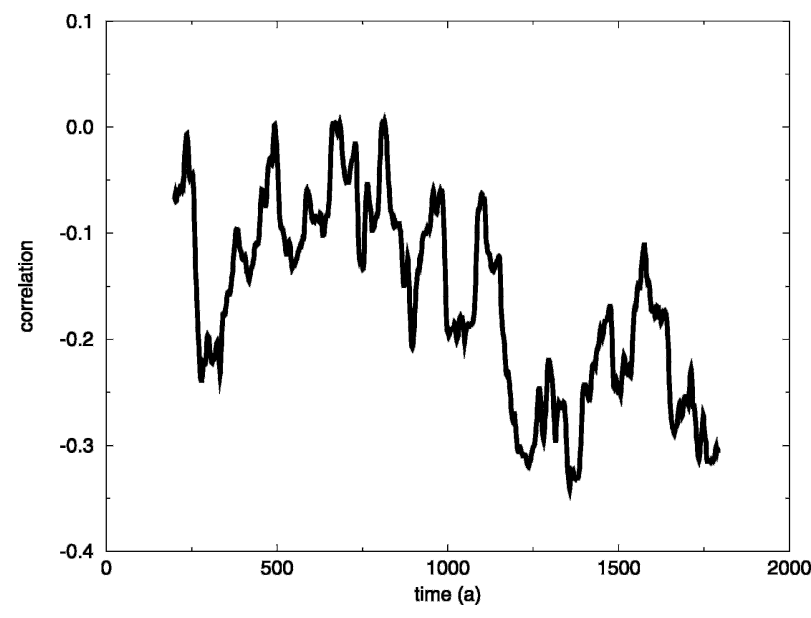

FIG. 7. Temporal evolution of the correlation between the annual Niño-3 SST anomaly and the North Pacific SST anomaly index. The correlations are based on low-pass-filtered values, applying an 11-yr running mean to the time series. A window length of $398 \mathrm{yr}$ was used and slid through the full 2000-yr-long record. Negative correlations exceeding -0.3 are significant at the $95 \%$ level according to a $t$ test.

negative, as expected from present-day El Niño events, but largely insignificant (negative correlations exceeding -0.3 are significant at the $95 \%$ level according to a $t$ test). Furthermore, some quite strong centennial variability is seen in the temporal evolution of the correlation. This supports the view that rather long records are needed to study the interactions between the Tropics and the midlatitudes.

Acknowledgments. The author thanks Drs. Noel Keenlyside and Dietmar Dommenget for fruitful discussions. This work was supported by the European Union's ENSEMBLES and DYNAMITE programs. The coupled model integrations were performed at the Deutsches Klimarechenzentrum.

\section{REFERENCES}

Barnett, T. P., D. W. Pierce, R. Saravanan, N. Schneider, D. Dommenget, and M. Latif, 1999: Origins of the midlatitude Pacific decadal variability. Geophys. Res. Lett., 26, 1453-1456.

Deser, C., A. S. Phillips, and J. W. Hurrell, 2004: Pacific interdecadal climate variability: Linkages between the Tropics and the North Pacific during boreal winter since 1900. J. Climate, 17, 3109-3124.

Frankignoul, C., P. Müller, and E. Zorita, 1997: A simple model of the decadal response of the ocean to stochastic wind stress forcing. J. Phys. Oceanogr., 27, 1533-1546.

Graham, N. E., 1994: Decadal-scale climate variability in the tropical and North Pacific during the 1970s and 1980s: Observations and model results. Climate Dyn., 10, 135-162.

Grötzner, A., M. Latif, A. Timmermann, and R. Voss, 1999: Interannual to decadal predictability in a coupled ocean- 
atmosphere general circulation model. J. Climate, 12, 26072624.

Gu, D., and S. G. H. Philander, 1997: Interdecadal climate fluctuations that depend on exchanges between the tropics and the extra-tropics. Science, 275, 805-807.

Hasselmann, K., 1976: Stochastic climate models. Part I. Theory. Tellus, 28, 473-485.

Latif, M., and T. P. Barnett, 1994: Causes of decadal climate variability over the North Pacific and North America. Science, 266, 634-637.

Mantua, N. J., S. R. Hare, Y. Zhang, J. M. Wallace, and R. C. Francis, 1997: A Pacific interdecadal climate oscillation with impacts on salmon production. Bull. Amer. Meteor. Soc., 78, 1069-1079.

Mestas-Nuñez, A. M., and D. B. Enfield, 1999: Rotated global modes of non-ENSO sea surface temperature variability. $J$. Climate, 12, 2734-2746.

Saravanan, R., and J. C. McWilliams, 1998: Advective oceanatmosphere interaction: An analytical stochastic model with implications for decadal variability. J. Climate, 11, 165-188.

Timmermann, A., M. Latif, R. Voss, and A. Grötzner, 1998: Northern Hemisphere interdecadal variability: A coupled air-sea mode. J. Climate, 11, 1906-1931.

, _ _ , A. Grötzner, and R. Voss, 1999: Modes of variability as simulated by a global climate model. Part I: ENSO-like climate variability and its low-frequency modulation. Climate Dyn., 15, 605-618.

Tourre, Y. M., Y. Kushnir, and W. B. White, 1999: Evolution of interdecadal variability in sea level pressure, sea surface temperature, and upper ocean temperature over the Pacific Ocean. J. Phys. Oceanogr., 29, 1528-1541.

_, B. Rajagopalan, Y. Kushnir, M. Barlow, and W. B. White, 2001: Patterns of coherent decadal and interdecadal climate signals in the Pacific basin during the 20th century. Geophys. Res. Lett., 28, 2069-2072.

Trenberth, K. E., and J. W. Hurrell, 1994: Decadal atmosphereocean variations in the Pacific. Climate Dyn., 9, 303-319.

Venzke, S., M. Münnich, and M. Latif, 2000: On the predictability of decadal changes in the North Pacific. Climate Dyn., 16, 379-392.

Voss, R., R. Sausen, and U. Cubasch, 1998: Periodically synchronously coupled integrations with the atmosphere-ocean general circulation model ECHAM3/LSG. Climate Dyn., 14, 249-266.

Zhang, R.-H., and S. Levitus, 1997: Structure and cycle of decadal variability of upper ocean temperatures in the North Pacific. J. Climate, 10, 710-727.

Zhang, Y., J. M. Wallace, and D. S. Battisti, 1997: ENSO-like interdecadal variability: 1900-93. J. Climate, 10, 1004-1020. 